\title{
O trâmite prioritário de patentes de instituições de ciência e tecnologia enquanto processo estratégico para a propriedade industrial nacional
}

\author{
The priority procedure for patents by science and technology institutions as a Strategic Process for \\ national industrial property \\ El procedimiento de prioridad para patentes por instituciones de ciencia y tecnología como proceso \\ estratégico para la propiedad industrial nacional
}

Recebido: 09/09/2021 | Revisado: 15/09/2021 | Aceito: 20/09/2021 | Publicado: 22/09/2021

\author{
Ricardo Maia do Amaral \\ ORCID: https://orcid.org/ 0000-0002-8094-2342 \\ Instituto Federal de Educação, Ciência e Tecnologia da Paraíba, Brasil \\ E-mail: ricardo.maia@academico.ifpb.edu.br \\ João Ricardo Freire de Melo \\ ORCID: https://orcid.org/0000-0001-8407-1188 \\ Instituto Federal de Educação, Ciência e Tecnologia da Paraíba, Brasil \\ E-mail: joao.melo@ifpb.edu.br
}

\begin{abstract}
Resumo
O sistema nacional de exploração da propriedade industrial, cuja proteção funciona mediante a concessão de patentes e registros, é relevante para o desenvolvimento tecnológico do país. No caso das patentes, o grande aumento de solicitações gera o que vem se denominando backlog, solicitações pendentes por mais tempo do que a duração pretendida. Como forma de combate ao backlog, o INPI vem aperfeiçoando o trâmite prioritário de processos. O objetivo deste trabalho é discutir a pertinência dos trâmites prioritários de patentes referentes a ICTs. A metodologia adotada nesta pesquisa fundamenta-se nos pressupostos de uma abordagem quali-quantitativa, configurando-se numa pesquisa de natureza básica, de objetivo exploratório, com procedimentos de coleta de dados realizados via pesquisa bibliográfica e documental. Verificamos que o backlog de patentes ainda é um sério problema que o Brasil enfrenta, com tendências de aumento na demanda por novas análises desses ativos. A iniciativa de fomentar um trâmite prioritário para as ICTs configura um processo estratégico nacional no escopo do sistema de inovação brasileiro que tende a promover benefícios, não só para essas instituições, como a geração, em algum momento, de bem-estar social. Palavras-chave: Institutos de ciência e tecnologia; Backlog de patentes; Trâmite prioritário; Processo estratégico; Sistema Nacional de Inovação.
\end{abstract}

\begin{abstract}
The national system for the exploitation of industrial property, whose protection works through the granting of patents and registrations, is relevant to the country's technological development. In the case of patents, the large increase in requests generates what has been called a backlog, requests pending for longer than the intended duration. As a way to fight backlog, the INPI has been improving the priority process of processes. The objective of this work is to discuss the relevance of the priority patent procedures related to ICTs. The methodology adopted in this research is based on the assumptions of a quali-quantitative approach, setting up a research of a basic nature, with an exploratory objective, with data collection procedures carried out through bibliographical and documentary research. We found that the patent backlog is still a serious problem that Brazil is facing, with an increasing demand for new analysis of these assets. The initiative to promote a priority procedure for ICTs configures a national strategic process within the scope of the Brazilian innovation system that tends to promote benefits, not only for these institutions, but also the generation, at some point, of social well-being.
\end{abstract}

Keywords: Science and technology institutes; Patent backlog; Priority procedure; Strategic process; National Innovation System.

\section{Resumen}

El sistema nacional de explotación de la propiedad industrial, cuya protección funciona mediante el otorgamiento de patentes y registros, es relevante para el desarrollo tecnológico del país. En el caso de las patentes, el gran aumento de solicitudes genera lo que se ha denominado un backlog, solicitudes pendientes por más tiempo de lo previsto. Como forma de combatir el atraso, el INPI viene mejorando el proceso de prioridad de procesos. El objetivo de este trabajo es discutir la relevancia de los procedimientos de patentes prioritarios relacionados con las TIC. La metodología adoptada en esta investigación se basa en los supuestos de un enfoque cuali-cuantitativo, configurando una 
investigación de carácter básico, con un objetivo exploratorio, con procedimientos de recolección de datos realizados a través de la investigación bibliográfica y documental. Descubrimos que la acumulación de patentes sigue siendo un problema grave al que se enfrenta Brasil, con una demanda creciente de nuevos análisis de estos activos. La iniciativa de promover un procedimiento prioritario para las TIC configura un proceso estratégico nacional en el ámbito del sistema de innovación brasileño que tiende a promover beneficios, no solo para estas instituciones, sino también la generación, en algún momento, de bienestar social.

Palabras clave: Institutos de ciencia y tecnología; Cartera de patentes; Procedimiento de prioridad; Proceso estratégico; Sistema Nacional de Innovación.

\section{Introdução}

O sistema nacional de exploração da propriedade industrial, cuja proteção funciona mediante a concessão de patentes e registros, é relevante para o desenvolvimento tecnológico do país. Faz parte integrante do sistema de proteção à propriedade intelectual e consiste em um conjunto de instrumentos jurídicos, não só nacionais como internacionais, que visam à proteção de ativos intangíveis da indústria, de forma a conferir um privilégio temporário aos autores de invenções, modelos de utilidades, desenhos industriais, indicações geográficas e marcas, mediante a garantia de exclusividade na exploração econômica dos objetos protegidos. Esse sistema protecionista favorece o investimento em pesquisa e desenvolvimento no setor da indústria, ao possibilitar o retorno financeiro aos que assumiram o risco da inovação.

Na Constituição de 1988 (Brasil, 1988), a proteção à propriedade industrial está situada no rol dos direitos fundamentais previstos no art. $5^{\circ}$, sendo especificamente tratada no seu inciso XXIX. Embora a patente configure-se no normativo legal como direito individual em que se dá exclusividade às pessoas físicas ou jurídicas que figurem como autores de uma invenção ou modelo de utilidade, o escopo maior da norma constitucional é incrementar o bem-estar social, por meio do incentivo para os inventores assumirem os riscos vinculados a investimentos em projetos de desenvolvimento de novas tecnologias e pela geração alternativa nos mercados, preços e qualidades melhores.

Segundo a Lei $\mathrm{n}^{\mathrm{o}}$ 5.648, de 11 de dezembro de 1970, o Instituto Nacional da Propriedade Industrial (INPI), autarquia federal vinculada ao Ministério da Economia, tem por finalidade principal executar as normas que regulam a propriedade industrial, tendo em vista a sua função social, econômica, jurídica e técnica, bem como pronunciar-se quanto à conveniência de assinatura, ratificação e denúncia de convenções, tratados, convênios e acordos sobre propriedade industrial (BRASIL, 1970). Dessa maneira, as responsabilizações da autarquia recaem sobre os registros de marcas, desenhos industriais, indicações geográficas, programas de computador e topografias de circuitos, as concessões de patentes e as averbações de contratos de franquia e das distintas modalidades de transferência de tecnologia.

Quando falamos especificamente em concessões de patentes, nos referimos a um tipo de propriedade intelectual feita para proteger soluções inventivas para problemas técnicos conhecidos. Soluções essas que geram objetos de recorrentes análises e que, por sua vez, envolvem assuntos como transferência de tecnologia, cooperação universidade-empresa, desenvolvimento econômico e social, criatividade e inventividade. A importância conferida à patente gera um elevado número de pedidos por esse ativo nos escritórios de Propriedade Intelectual em todo mundo. Dessa maneira, existe uma necessidade para que os exames requeridos para efetuar essas concessões sejam realizados de forma eficiente. 
Research, Society and Development, v. 10, n. 12, e300101220421, 2021

(CC BY 4.0) | ISSN 2525-3409 | DOI: http://dx.doi.org/10.33448/rsd-v10i12.20421

Tabela 1. Número de pedidos de patentes requeridas ao INPI entre os anos de 2013 e 2020.

\begin{tabular}{llll}
\hline Período & PATENTES & \\
\cline { 2 - 4 } & Patentes de Invenção & Modelos de Utilidade & Certificado de Adição \\
\hline 2013 & 30.884 & 3.032 & 134 \\
2014 & 30.342 & 2.734 & 106 \\
2015 & 30.219 & 2.718 & 106 \\
2016 & 28.010 & 2.936 & 74 \\
2017 & 25.658 & 2.918 & 91 \\
2018 & 24.857 & 2.587 & 107 \\
2019 & 25.396 & 2.824 & 98 \\
2020 & 24.339 & 2.663 & 89 \\
\hline
\end{tabular}

Fonte: INPI (2021c)

Como observado na Tabela 1, usando uma média de solicitações de patentes de invenção entre 2013 e 2020, obtemos o valor de 27.463 requisições do tipo. O grande número de solicitações acaba por gerar uma demanda não atendida por esse serviço nos escritórios de Propriedade Intelectual, não somente no Brasil como em todo o mundo.

\subsection{Backlog de Patentes}

O dicionário Oxford (2018), define a expressão "backlog” tratando-a como: “A huge backlog of work”, traduzindo: “Um monte de trabalho acumulado". Definição similar à de Barbosa (2013), que considera backlog, na seara das patentes, como o nível de pedidos que, devido à falta de ação do examinador, ficam pendentes por mais tempo do que a duração pretendida. Observa-se que o termo backlog está relacionado à acumulação de trabalho em um determinado intervalo de tempo. Sendo considerado, portanto, para proteção do direito, um empecilho que retarda a concessão de patentes no país. Pode ser compreendido como a quantidade de pedidos de patentes pendentes por duração maior do que a almejada, por examinador (Guedes \& Sartori, 2017).

Segundo dados de 2019 do IP5, entidade que reúne os cinco principais escritórios de propriedade intelectual do mundo, aproximadamente 4,7 milhões de pedidos estavam pendentes (aguardando pedido de exame ou com exame pendente) nos seus respectivos escritórios (IP5, 2019).

Tabela 2. Exames pendentes, em 2018 e 2019, nos principais escritórios de propriedade intelectual*.

\begin{tabular}{llllll}
\hline Ano & EPO & JPO & KIPO & CNIPA & UPSTO \\
\hline & & & & & \\
2018 & 371.884 & 168.679 & 166.878 & 1.968 .203 & 546.792 \\
2019 & 335.293 & 173.494 & 174.064 & 2.218 .145 & 578.138 \\
Diferença (\%) & $-9,84$ & 2,85 & 4,31 & 12,70 & 5,73 \\
\hline
\end{tabular}

Notas:

*Os principais escritórios de propriedade intelectual são:

European Patent Office - EPO,

Japan Patent Office - JPO,

Korean Intellectual Property Office - KIPO,

China National Intellectual Property Administration - CNIPA,

United States Patent and Trademark Office - UPSTO.

Fonte: Elaboração própria a partir de dados obtidos do IP5 Statistics Report (2019).

Na Tabela 2, observamos que ocorreu, entre os anos de 2018 e 2019, um aumento na demanda de exames pendentes de análise nos escritórios do Japão (2,85\%), Korea (4,31\%), China (12,70\%) e Estados Unidos (5,73\%) e um decréscimo apenas no escritório Europeu (-9,84\%). 
No Brasil, deve-se ressaltar o papel fundamental do INPI para sociedade, pois suas decisões podem impactar diretamente nos cenários sociais e econômicos, e que, diante deste contexto, o backlog é considerado um sério problema. Por se tratar de um entrave ao sistema de patentes no Brasil, Santos et al. (2015), Garcez e Moreira (2017) partilham da mesma visão ao constatar que o backlog têm sido fator preocupante para os usuários, pois potencializa a insegurança jurídica e desestimula os investimentos, criando obstáculos à inovação tecnológica e ao desenvolvimento econômico.

A título de exemplo, mesmo com esforço empregado de combate ao backlog, o prazo médio para decisão final de um pedido de patente em 2017 era de aproximadamente 10,8 anos, já em 2018 é verificada uma redução do tempo médio de decisão para 10,4 anos, conforme demonstrado na Figura 1.

Figura 1. Tempo de Decisão por Divisão Técnico do INPI.

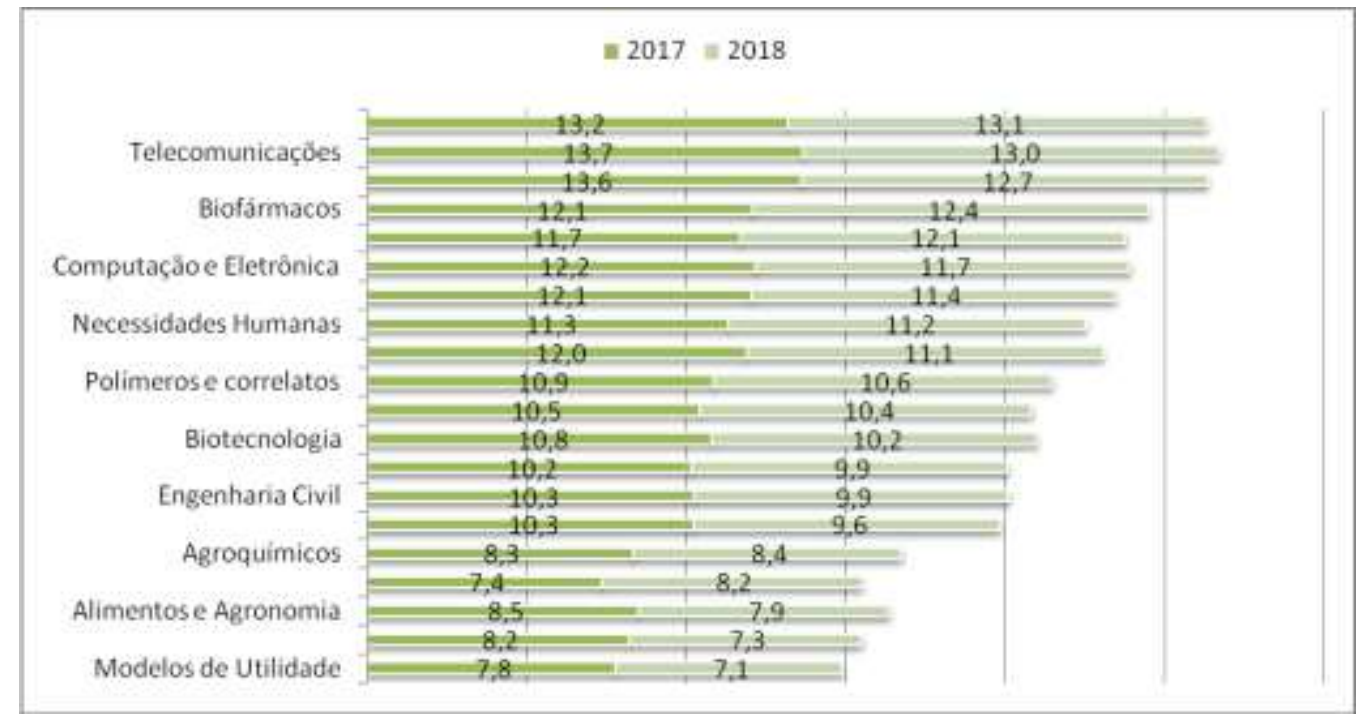

Fonte: INPI (2017/2018)

Observa-se, entretanto, que os efeitos do backlog são ambíguos, apresentando visões positivas e negativas acerca do assunto. A dilatação excessiva do tempo de exame favorece o depositante que não possui todos os ativos necessários para a comercialização da invenção ou esteja em busca de parceiros comerciais. Sendo o backlog benéfico quando a tecnologia objeto da patente esteja dependente dos resultados posteriores em Pesquisa e Desenvolvimento (P\&D).

Por outro lado, os efeitos negativos causados pelo backlog afetam os competidores e consumidores, pois o atraso na avaliação do pedido de patente prejudica a mobilização de recursos do competidor para o desenvolvimento de tecnologias alternativas - aquelas requeridas ou a reprodução da tecnologia requerida pela incerteza gerada quanto à validade e escopo da proteção, caso obtida junto ao escritório de patentes (De Abreu, 2017).

Tatum et al.(2018) apontam o backlog com um gargalo para inovação no país, principalmente quanto a tecnologias de ponta para bens de consumo em termos globais, como tecnologias móveis e eletrônicos de um modo geral, apresentam uma mudança de curta duração em lançamentos contínuos, deixando rapidamente para trás as tecnologias depositadas para análise. Opinião compartilhada por Garcez e Moreira (2017) que afirmam ser preciso criar um processo ágil e de qualidade na concessão de patentes, pois assim, favorece o desenvolvimento econômico por meio da inovação, principalmente em setores mais sensíveis a mudanças tecnológicas, como máquinas industriais e aparelhos eletrônicos.

O atraso para decidir sobre a validade das patentes no sistema patentário brasileiro é provocado por um conjunto de fatores externos ao país como a dinâmica crescente de novos depósitos de patentes junto ao INPI, principalmente de depositantes não residentes, desta forma, superando a capacidade operacional do Instituto (De Abreu, 2017). Esta tendência 
posiciona o Brasil na décima posição, entre os países que mais recebem pleitos de patentes no âmbito global, provocando o acúmulo excessivo de pedidos de patentes aguardando decisão (Wipo, 2016).

Como alternativa para resolução dos empecilhos criados pela existência do backlog, verifica-se a qualificação e efetivação de recursos humanos responsáveis pelas análises, a informatização de processos de registro e o lançamento de procedimento para simplificação do deferimento de patentes (Guedes \& Sartori, 2017). A própria regulamentação e execução do exame prioritário de patentes pelos escritórios de patentes é uma providência recorrente para mitigar o backlog, pois os requerimentos de patentes sobre tecnologias mais relevantes para o Sistema Nacional de Inovação - SNI, podem ser examinados em ordem de trabalho preferencial, reduzindo as incertezas de terceiros em participar de tais mercados tecnológicos, contribuindo para o estímulo à competição e o acesso (De Abreu, 2017).

No âmbito do INPI, a Diretoria de Patentes, Programas de Computador e Topografias de Circuitos Integrados (DIRPA) iniciou o Programa de Combate ao Backlog de Exame de Patentes visando à redução substantiva do número de pedidos de patente de invenção com exame requerido e pendente de decisão, em um período de dois anos. É importante pontuar que se configura como backlog os pedidos arquivados, em exame técnico, exames aptos para o primeiro exame, exames formais ou exames da ANVISA. Obviamente, não entram no cômputo, os pedidos que já foram decididos ou que foram arquivados definitivamente.

Figura 2. Evolução do Plano de Combate ao Backlog de Patentes do INPI no período de Setembro de 2019 a Junho de 2021.

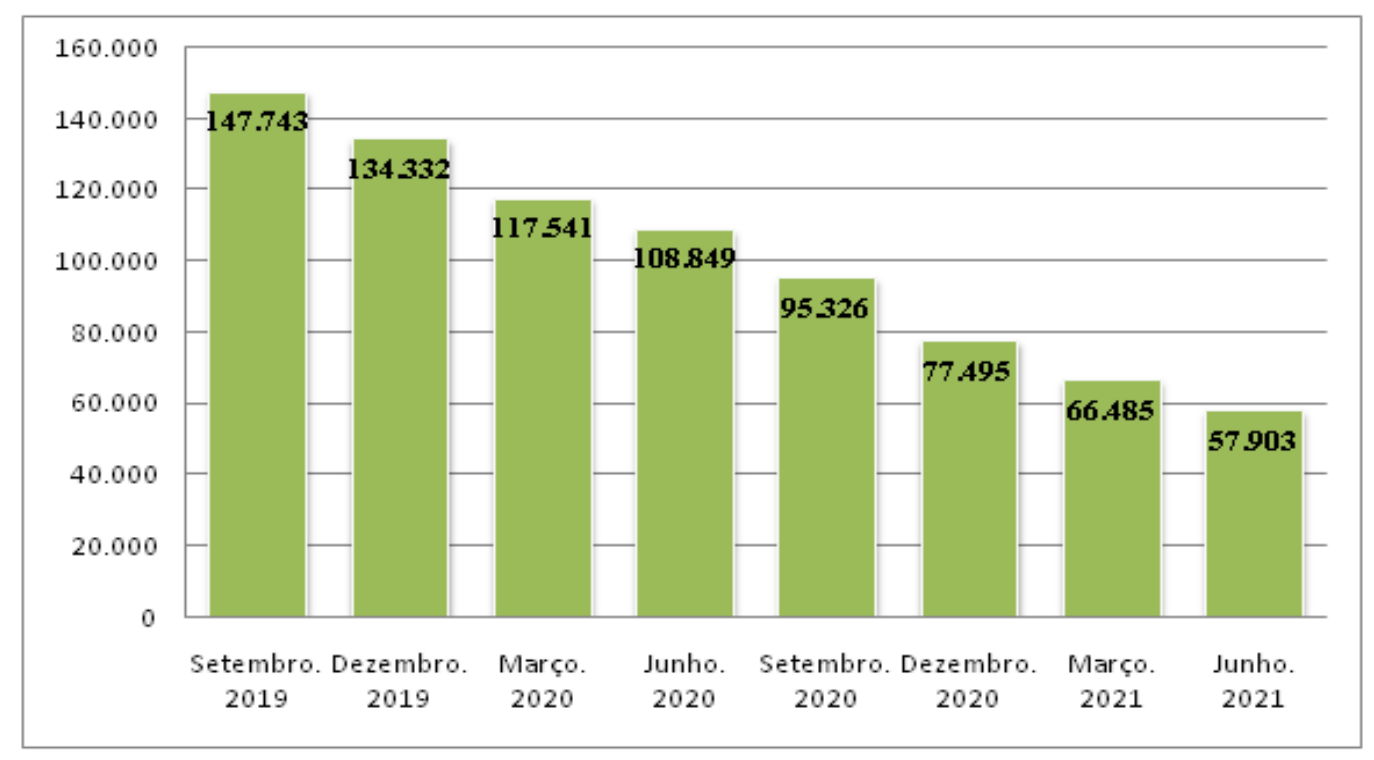

Fonte: Elaboração própria baseada na Evolução do Plano de Combate ao Backlog de Patentes, disponível em INPI (2021a): https://www.gov.br/inpi/pt-br/servicos/patentes/plano-de-combate-ao-backlog/historico-do-plano-de-combate-ao-backlog-de-patentes, acessado em (30/08/2021).

Como pode ser visto na Figura 2, de setembro de 2019 a junho de 2021, houve uma redução de aproximadamente 39,19\% como fruto do Plano de Combate ao Backlog de Patentes do INPI.

Para resolver o problema dos acúmulos de solicitação de patentes, há uma tendência que os escritórios nacionais trabalhem juntos para tentar reduzir a quantidade de repetição de trabalho semelhante que ocorre entre os escritórios para es ses pedidos de patentes. Outros pontos chaves para o aumento da produtividade dos exames requeridos foram à simplificação dos procedimentos de exame, um novo plano básico de exigências preliminares, a adoção do programa de gestão "modalidade por tarefa com dispensa de controle de ponto". 


\subsection{Trâmite Prioritário de Processos}

Ainda, como parte do Plano de Combate ao Backlog de Patentes, o INPI vem aperfeiçoando o trâmite prioritário de processos que envolvem a proteção de direitos de propriedade industrial pelo uso de patentes. Esse tipo de trâmite possibilita os exames prioritários, processos nos quais os pedidos de patente possuem um tempo de concessão reduzido, com o objetivo de acelerar não somente os exames como todo o trâmite. A admissão ou não ao trâmite prioritário, não interfere em nada no direito patentário.

Segundo Musskopf (2019), com a publicação na Resolução INPI PR nº 132 de 2006, o INPI regulamentou pela primeira vez o serviço de exame prioritário de pedidos de patente. Esta Resolução disciplinava inicialmente a priorização do exame de mérito de pedidos de patente por razão da idade, depositante acusa contrafação, terceiros acusados de reprodução indevida, e interesse público.

Atualmente, a portaria INPI $n^{\circ} 247$, de 22 de junho de 2020, publicada na RPI $n^{\circ} 2582$, de 30 de junho de 2020, disciplina o trâmite prioritário de processos de patente. As modalidades descritas no Título II da portaria são descritas dessa maneira: idosos; portadores de deficiência física ou mental; portadores de doença grave; MEI (Microempreendedor Individual), ME (Microempresa), EPP (Empresa de Pequeno Porte); ICT (Instituição Científica, Tecnológica e de Inovação); startups; tecnologias verdes; tecnologias para tratamento de saúde; tecnologias para tratamento do Covid-19; Tecnologia Solicitada pelo Ministério da Saúde; Tecnologia de Interesse Público ou Emergência Nacional; Liberações de recurso financeiro; depositantes que acusam contrafação; terceiros acusados de contrafação, usuários anteriores da tecnologia e famílias de patente iniciadas no Brasil. Como notado, os trâmites podem ser categorizados em razão do depositante, da situação, da tecnologia ou da cooperação (INPI, 2020a). Como documentação complementar, a Instrução Normativa INPI/DIRPA n $2 / 2020$, publicada na mesma RPI, estabelece os procedimentos administrativos relativos à avaliação dos requerimentos de trâmite prioritário de processos de patente no âmbito da DIRPA (INPI, 2020b).

\section{Metodologia}

Em meio a uma demanda crescente por pedidos de análise de patentes, o presente artigo tem como objetivo discutir a pertinência dos trâmites prioritários de patentes a ICTs. Para o alcance do objetivo proposto, a metodologia adotada nesta pesquisa fundamenta-se nos pressupostos de uma abordagem quali-quantitativa (ESTRELA, 2018), uma vez que incluem dados quantitativos acerca dos números de pedidos de patentes, backlogs e, também, os aspectos qualitativos relacionados à discussão sobre as requisições de trâmites prioritários dessas patentes advindas de ICTs.

O estudo está configurando numa pesquisa de natureza básica, de objetivo exploratório, com procedimentos de coleta de dados realizados via pesquisa bibliográfica e documental. Utilizamos, para essa etapa da pesquisa, dados secundários obtidos por meio de consultas em fontes de dados institucionais disponibilizados pelo IP5 Statistics Report, além de buscas prospectivas sobre requisições de patentes no Brasil com trâmite prioritário de ICTs, considerando os registros no repositório do INPI.

Foi realizada a tabulação e tratamento dos dados coletados com apoio de planilhas eletrônicas, com a posterior organização dos achados de pesquisa. Para tratamento dos dados, empregamos análises de estatística descritiva.

\section{Resultados e Discussão}

Podemos observar, no Quadro 1, as modalidades de trâmites prioritários categorizados por tipo de exame. 
Quadro 1. Modalidades de trâmites prioritários categorizados por tipo de exame.

\begin{tabular}{|c|c|}
\hline Tipo de Exame & Motivo \\
\hline \multirow{3}{*}{ Exame Prioritário } & Processo pertencente à pessoa física com idade igual ou superior a 60 anos. \\
\hline & Processo pertencente à pessoa física com deficiência física ou mental. \\
\hline & Processo pertencente à pessoa física portadora de doença grave. \\
\hline \multirow{13}{*}{ Exame prioritário estratégico } & Processos pertencentes a Microempresas e/ou Empresas de pequeno porte. \\
\hline & Processos pertencentes a Instituições Científicas, Tecnológicas e de Inovação. \\
\hline & Processos pertencentes a Startups. \\
\hline & Processos cuja concessão é condição para obter recursos financeiros. \\
\hline & Processo cujo objeto é reproduzido por terceiros sem a autorização. \\
\hline & Processos cujo terceiros estão sendo acusados de contrafação. \\
\hline & Processos que há usuários anteriores da tecnologia. \\
\hline & Processos de tecnologia resultante de financiamento público. \\
\hline & Processos de tecnologia disponível no mercado. \\
\hline & Processos que pleiteiam a proteção de tecnologia verde. \\
\hline & Processos cujo objeto é produto para tratamento de doenças específicas. \\
\hline & Processos cujo objeto é produto para tratamento do Covid-19. \\
\hline & Processos de famílias de patente cuja proteção foi inicialmente requerida no Brasil. \\
\hline Exame prioritário colaborativo & Processos cuja matéria foi considerada patenteável por um escritório parceiro. \\
\hline
\end{tabular}

Fonte: Elaboração própria baseada no Quadro de modalidades de trâmite prioritário, disponível em INPI (2020): https://www.gov.br/inpi/pt-br/servicos/patentes/plano-de-combate-ao-backlog/historico-do-plano-de-combate-ao-backlog-depatentes acessado em (30/08/2021).

No quadro apresentado, podemos observar categorias de exames nos trâmites prioritários, quais sejam: exame prioritário, exame prioritário estratégico e exame prioritário colaborativo. O foco deste trabalho está relacionado a analisar os trâmites prioritários estratégicos vinculados a ICTs.

$\mathrm{Na}$ perspectiva de avanços em relação aos processos de trâmites prioritários, o INPI vem permitindo o trâmite prioritário de pedidos de patente pertencentes à ICTs, conforme definição do inciso $\mathrm{V}$, do artigo $2^{\circ}$, da Lei $\mathrm{n}^{\circ} 13.243$, de 11 de janeiro de 2016 (Brasil, 2016). Antes como projetos piloto e hoje como serviço permanente da autarquia, a iniciativa facilita a inserção de produtos e serviços inovadores desenvolvidos pelas ICTs e mitiga os efeitos negativos do atraso do INPI na decisão de pedidos de patente para este grupo específico de depositantes. 
Research, Society and Development, v. 10, n. 12, e300101220421, 2021

(CC BY 4.0) | ISSN 2525-3409 | DOI: http://dx.doi.org/10.33448/rsd-v10i12.20421

Quadro 2. Processos de trâmites prioritários estratégicos.

\begin{tabular}{|c|c|c|}
\hline Categoria & Motivo & Depositante ou Razão \\
\hline \multirow{3}{*}{$\begin{array}{l}\text { Em razão do } \\
\text { depositante }\end{array}$} & $\begin{array}{l}\text { Processos pertencentes a Microempresas e/ou Empresas de pequeno } \\
\text { porte. }\end{array}$ & Depositante MEI, ME ou EPP \\
\hline & $\begin{array}{l}\text { Processos pertencentes a Instituições Científicas, Tecnológicas e de } \\
\text { Inovação. }\end{array}$ & Depositante ICT \\
\hline & Processos pertencentes a Startups. & Depositante Startup \\
\hline \multirow{6}{*}{$\begin{array}{l}\text { Em razão da } \\
\text { situação }\end{array}$} & $\begin{array}{l}\text { Processos cuja concessão é condição para obter recursos } \\
\text { financeiros. }\end{array}$ & Liberação de recurso financeiro \\
\hline & Processo cujo objeto é reproduzido por terceiros sem a autorização. & Depositante acusa contrafação \\
\hline & Processos cujo terceiros estão sendo acusados de contrafação. & Terceiro acusado de contrafação \\
\hline & Processos que há usuários anteriores da tecnologia. & Usuário anterior da tecnologia \\
\hline & Processos de tecnologia resultante de financiamento público. & $\begin{array}{l}\text { Tecnologia resultante de financiamento } \\
\text { público }\end{array}$ \\
\hline & Processos de tecnologia disponível no mercado. & Tecnologia disponível no mercado \\
\hline \multirow{3}{*}{$\begin{array}{l}\text { Em razão da } \\
\text { tecnologia }\end{array}$} & Processos que pleiteiam a proteção de tecnologia verde. & Tecnologia verde \\
\hline & $\begin{array}{l}\text { Processos cujo objeto é produto para tratamento de doenças } \\
\text { específicas. }\end{array}$ & Tecnologia para tratamento de saúde \\
\hline & Processos cujo objeto é produto para tratamento do Covid-19. & $\begin{array}{l}\text { Tecnologia para tratamento do Covid- } \\
19\end{array}$ \\
\hline $\begin{array}{l}\text { Em razão da } \\
\text { cooperação }\end{array}$ & $\begin{array}{l}\text { Processos de famílias de patente cuja proteção foi inicialmente } \\
\text { requerida no Brasil. }\end{array}$ & Família de patentes iniciada no Brasil \\
\hline
\end{tabular}

Fonte: Elaboração própria baseada no Quadro de modalidades de trâmite prioritário, disponível em INPI (2020b): https://www.gov.br/inpi/pt-br/servicos/patentes/tramite-prioritario/modalidades-de-tramite-prioritario-de-patentes, acessado em $(30 / 08 / 2021)$.

Verificando os trâmites prioritários registrados no INPI, podemos identificar que os processos pertencentes à categoria de ICTs representam apenas uma ínfima parcela no cômputo geral. 
Figura 3. Quantidade de trâmites prioritários no INPI.

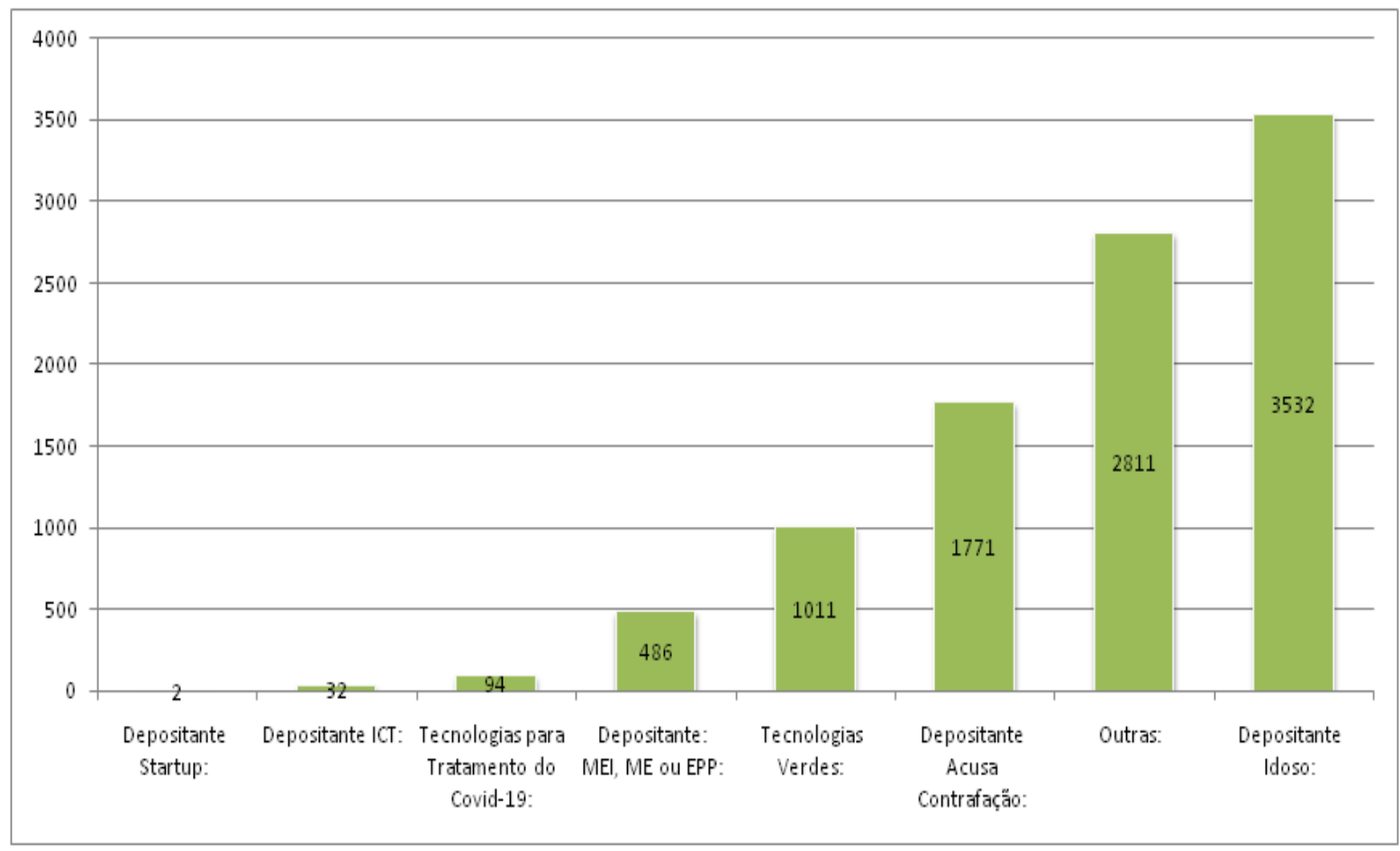

Fonte: INPI (2021c).

Quando analisamos os processos de trâmites prioritários estratégicos em razão de sua categoria (depositante), podemos identificar que temos apenas 6,2\% relacionados à ICTs, enquanto a grande maioria dos processos de trâmites prioritários estratégicos em razão de sua categoria (depositante) é relacionada a Microempresas e/ou Empresas de pequeno porte.

Quadro 3. Processos de trâmites prioritários estratégicos em razão do depositante.

\begin{tabular}{|clcc|}
\hline Categoria & \multicolumn{1}{c}{ Motivo } & Quantidade & Percentual \\
\hline \multirow{2}{*}{ Em razão do depositante } & Processos pertencentes a Microempresas e/ou Empresas de pequeno porte. & 486 & 93,5 \\
& Processos pertencentes a Instituições Científicas, Tecnológicas e de Inovação. & 32 & 6,2 \\
& Processos pertencentes a Startups. & 02 & 0,4 \\
\hline
\end{tabular}

Fonte: INPI (2021).

Há uma parcela ainda muito pequena de processos vinculados a ICTs. Um fato que talvez explique tal observação é que o Projeto Piloto de Patentes pertencentes a Microempresas e/ou Empresas de pequeno porte data de 2006, enquanto o Projeto Piloto Patentes ICTs foi normatizado em 2016. Ocorre possivelmente, dentro das ICTs ou mesmo dos Núcleos de Inovação Tecnológica, um desconhecimento sobre a possibilidade de se recorrer a esse benefício ou mesmo uma não familiaridade com a natureza do processo. 
Figura 4. Tempo Médio Entre o Requerimento de Prioridade e a Decisão do INPI.

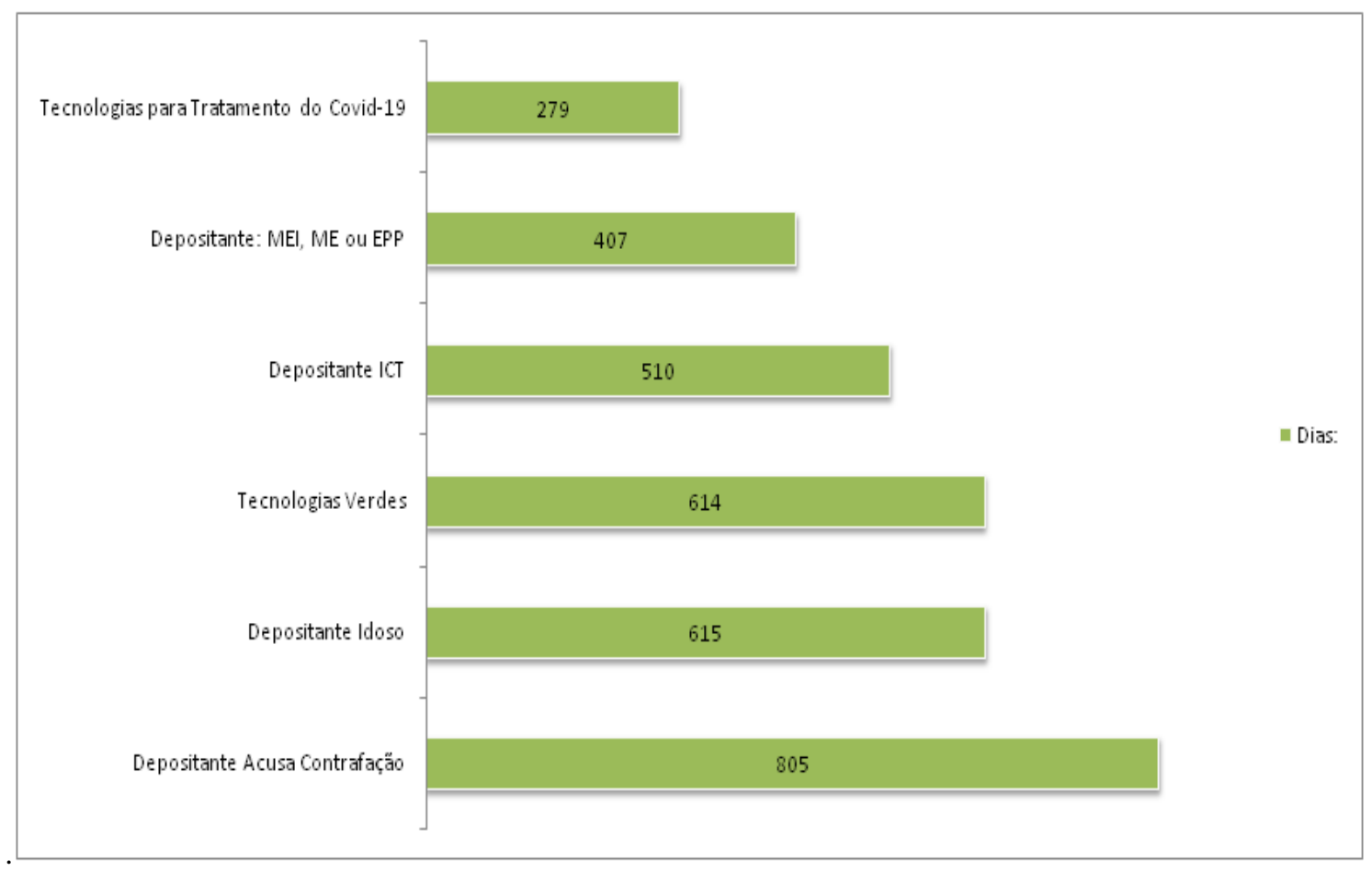

Fonte: INPI (2021).

O tempo médio entre o requerimento de trâmite prioritário e a decisão final por parte do INPI é expressivamente reduzida, quando comparada com as decisões do trâmite normal, conforme demonstrado anteriormente na figura 1, o tempo médio para decisão em 2017 era de 3.893 dias, o que equivale a 10,8 anos, em relação a 2018, ocorreu uma pequena redução em relação ao ano anterior, 3.770 dias ou 10,4 anos. Os prazos para alguns trâmites prioritários no INPI variam como demonstrado na figura 4, entre 279 dias para as Tecnologias para tratamento do Covid-19 e 805 dias para os Depositantes acusa contrafação. Para exemplificar a expressiva celeridade dos trâmites prioritários nas decisões por parte do INPI, o trâmite prioritário das Tecnologias para tratamento do Covid-19, são quase 14 vezes mais céleres em relação à média das decisões tomadas no INPI em 2017 para o trâmite normal.

\section{Conclusão}

O backlog de patentes desencoraja a inovação, potencializa a insegurança jurídica e desestimula os investimentos, reduzindo a eficácia de um sistema de patentes em diversas maneiras e impondo custos a todos os atores envolvidos. Dessa forma, cria obstáculos à inovação tecnológica e ao desenvolvimento econômico de um país.

A fim de minimizar o custo imposto aos atores do sistema de inovação, o INPI vem buscando alternativas para diminuir essa demanda sempre crescente pelo procedimento patentário. Nas iniciativas de solução apresentadas pelo órgão, analisamos o trâmite prioritário destinados às ICTs. Essas instituições têm um papel preponderante no Sistema Nacional de Inovação. Representam um ator dentro do sistema de inovação, com a função primordial de construir ligações promissoras de cooperação entre as empresas, governo e academia, adquirindo uma relevância crescente nas demandas sociais das mais diversas áreas do conhecimento.

Atribuir a essas instituições um caminho prioritário a fim de que o tempo entre a avaliação do requerimento e a decisão final de deferimento ou indeferimento das patentes seja reduzido substancialmente é fator determinante na exploração da propriedade industrial produzida nesses ambientes. A iniciativa prevê que ocorra um aumento de requerimentos prioritários 
pelas ICTs promovendo, dessa maneira, a inserção de produtos e serviços inovadores desenvolvidos por instituições de ciência e tecnologia brasileira no mercado global. Fato relevante no momento que há um predomínio de não residentes nos depósitos de patentes no Brasil, fato observado logo após a introdução da atual lei de propriedade industrial no país.

Importante pontuar também a conversão dos antigos requerimentos por "exames prioritários" ao novo modelo de "trâmite prioritário". O trâmite envolve todas as atividades do processo de patenteamento - desde a apresentação da documentação para o depósito até o fim da tramitação no instituto (arquivamento, indeferimento ou extinção), diferentemente do que ocorria no antigo "exame prioritário" que era restrito aos pedidos de patente aguardando o exame técnico.

Em resumo, podemos identificar que o backlog de patentes ainda é um sério problema que o Brasil enfrenta, com tendências de aumento na demanda por novas análises desses ativos. A iniciativa de fomentar um trâmite prioritário para as ICTs configura um processo estratégico nacional no escopo do sistema de inovação brasileiro que tende a promover benefícios, não só para essas instituições, como a geração, em algum momento, de bem-estar social.

Entendemos que há um apreço crescente pela inovação nas ICTs. Portanto essas entidades precisam prezar com igual esforço para proteger sua propriedade intelectual. Nosso estudo se limitou a discutir como o Trâmite Prioritário pode ajudar nessa proteção das patentes, mas ainda há muito a se pensar sobre estratégias de proteção de Propriedades Intelectuais nessas instituições, configurando-se, dessa forma, em trabalhos futuros.

\section{Referências}

Barbosa, D. B. (2013). A inexplicável política pública por trás do parágrafo único do art. 40 da Lei de Propriedade Industrial. Denis Borges Barbosa. https://www.dbba.com.br/wp-content/uploads/a-inexplicvel-poltica-pblica-por-trs-do-pargrafo-nico-do-art.-40-pargrafo-nico-do-cpi.96-agosto-de-2013.pdf.

Brasil. (1970). Lei no 5.648, de 11 de dezembro de 1970. Cria o Instituto Nacional da Propriedade Industrial e dá outras providências. Diário Oficial da República Federativa do Brasil, DF, 14 dez. 1970. http://www.planalto.gov.br/ccivil_03//Leis/L5648.htm.

Brasil. (1988). Constituição da República Federativa do Brasil de 1988, publicada em 05 de outubro de 1988. Congresso Nacional: Brasília. http://www.planalto.gov.br/ccivil_03/Constituicao/Constituicao.htm.

Brasil. (2016). Lei $\mathrm{n}^{\circ}$ 13.243, de 11 de janeiro de 2016. Dispõe sobre estímulos ao desenvolvimento científico, à pesquisa, à capacitação científica e tecnológica e à inovação. http://www.planalto.gov.br/ccivil_03/_ato2015-2018/2016/lei/113243.htm.

de Abreu, J. C. (2017). Prospecção tecnológica aplicada na otimização da concessão de patentes no Brasil: estudo de caso em patentes de medicamentos imunossupressores. [Tese de Doutorado, Universidade Federal do Rio de Janeiro, Instituto de Economia]. http://bibliotecadigital.anvisa.ibict.br/jspui/handle/123456/335.

Estrela, C. (2018). Metodologia científica: ciência, ensino, pesquisa. Editora Artes Médicas.

Garcez, S. S., \& Moreira, J. D. J. D. S. (2017). O backlog de patentes no Brasil: o direito à razoável duração do procedimento administrativo. Revista Direito $G V, 13,171-203$. http://dx.doi.org/10.1590/2317-6172201708.

Garcez, S. S., Eloy, B. R., \& Santos, J. A. B. D. (2021). A Qualidade dos Privilégios Patentários Concedidos no Brasil Sob a Ótica das Ações Judiciais de Nulidade de Patentes. Revista Direito GV, 17. https://doi.org/10.1590/2317-6172202116.

Guedes, I. L. B., \& Sartori, R. (2017). Backlog: Razões, Impactos e Soluções. X EPCC - Encontro Internacional de Produção Científica, Maringá, Brasil. http://rdu.unicesumar.edu.br/bitstream/123456789/1474/1/epcc--79485.pdf.

INPI. (2017). Relatório de Atividades INPI 2017. https:/www.gov.br/inpi/pt-br/composicao/arquivos/relatorio-de-atividades-inpi-2017-versao-portugues.pdf.

INPI. (2018). Relatório de Atividades INPI 2018. https://www.gov.br/inpi/pt-br/assuntos/noticias/inpi-divulga-relatório-2018-com-dados-consolidados-do-ano /Relatório de Atividades 2018.pdf/view.

INPI. (2020). Portaria n ${ }^{\circ}$ 247/2020, de 22 de junho de 2020. Disciplina Trâmite Prioritário de Processos de Patente no âmbito do INPI. Rio de Janeiro: 2020a. https://www.gov.br/inpi/pt-br/central-de-conteudo/noticias/PortariaPR24722.06.20RPI258230.06.20.pdf.

INPI. (2020). Instrução Normativa no 2/2020, de 26 de junho de 2020. Estabelece os Procedimentos administrativos Relativos à Avaliação dos Requerimentos de Trâmite Prioritário de Processos de Patente no Âmbito da DIRPA. Rio de Janeiro: 2020b. https://www.gov.br/inpi/ptbr/servicos/patentes/legislacao/legislacao/PrioritriosIIINDIRPA226.06.20RPI258230.06.20.pdf

INPI. (2020). Estatísticas Gerais, 2020c. https://www.gov.br/inpi/pt-br/servicos/patentes/tramite-prioritario/estatisticas-gerais.

INPI. (2021). Evolução do Plano de Combate ao Backlog de Patentes, 2021a. https://www.gov.br/inpi/pt-br/servicos/patentes/plano-de-combate-ao-backlog /historico-do-plano-de-combate-ao-backlog-de-patentes. 
Research, Society and Development, v. 10, n. 12, e300101220421, 2021

(CC BY 4.0) | ISSN 2525-3409 | DOI: http://dx.doi.org/10.33448/rsd-v10i12.20421

INPI. (2021). Modalidades de Trâmite Prioritário, 2021b. https://www.gov.br/inpi/pt-br/servicos/patentes/tramite-prioritario/modalidades-de-tramiteprioritario-de-patentes.

INPI. (2021). Presidência. Diretoria Executiva. Assessoria de Assuntos Econômicos (AECON). Boletim mensal de propriedade industrial: estatísticas preliminares. (1). INPI, 2021c. https://www.gov.br/inpi/pt-br/acesso-a-informacao/pasta-x/boletim-mensal/arquivos/documentos/boletim-mensal-depropriedade-industrial_14-07-2021.pdf.

IP5. (2020). IP5 Statistics Report 2019. EPO, 2020.

Melo, J. R. F. de. (2020) A Relação entre Governo, Empresas e o Sistema Científico e Tecnológico como Prática de Inovação Aberta na Pesquisa Aplicada: o Modelo Fraunhofer. Revista Gestão, Inovação e Negócios, Anápolis, v. 6, n. 2, p. 51-63, 2020. DOI: https://doi.org/10.37951/2358-9868.2020v6i2.

Musskopf, D. B. (2019). Estudo sobre o projeto-piloto de uniformização da petição e avaliação dos requerimentos de trâmite prioritário de processo de patente no INPI. [TCC de Especialização, Universidade Federal do Rio Grande do Sul, Escola de Administração]. https://www.lume.ufrgs.br/handle/10183/212536.

OXFORD. (2018). Oxford Advanced Learner's Dictionary. Oxford University Press, 2018.

Santos, I. J. S., Amaral, Y. S., Alves, F. F., \& Gava, R. (2015). Propriedade Intelectual na Universidade Federal de Viçosa: uma análise da gestão por meio dos documentos de patentes. Cadernos de Prospecção, 8 (2), 255.

Tatum, C. T. S., Tatum, L. M. M., Fabris, J. P., Russo, S. L., \& Jesus, V. D. (2018). Patentes do Brasil: história e atualidades. Propriedade intelectual e gestão de tecnologias. 1, 15-30, 2018.

WIPO. (2016). WIPO IP Facts and Figures 2016: Economics and Statistics Series. Geneva: WIPO, 2016. https://www.wipo.int/edocs/pubdocs/en/wipo_pub_ 943_2016. 